\title{
An (Almost) Perfectly Competitive Health Care Model for Patients that Minimizes Cost, Maximizes Satisfaction, Manages Medical Payments, and Generates Health Care Competition
}

\author{
Ian J. Shepherd \\ Abilene Christian University \\ Ethan Shepherd \\ Abilene Regional Hospital
}

The American health care system does not operate in an actual free market environment. The patient cannot manage his or her healthcare services and control his or her costs. This paper will discuss three of the requirements for perfect competition: (1) Many buyers, (2) Many sellers and (3) Perfect information. The meeting place for the solution to these requirements will generate an almost perfectly competitive market for medicine and return almost complete control to the patient. This meeting place will be an online auction/marketplace service. The service will act as a reverse auction or marketplace with competing providers bidding down prices to fill available slots in their services. The system will use current medical coding numbers to allow comparative pricing. Services can be bundled or sought individually by both the patient and the provider. Patients can choose how long to wait, how far to travel, and how much they want to pay before deciding on the provider.

\section{INTRODUCTION}

The current health care system does not operate in an actual free market environment. The patient cannot manage his or her healthcare services and control his or her costs. The patient is essentially disenfranchised from the decision process under current markets, methods, and controls. Medical providers are constrained by regulation, insurance requirements, and a general lack of patient knowledge regarding health care availability. These disconnects lead to a system where (although services provided in the U.S.A. are the best in the world) the costs to patients are rising, provider profits are declining, and both patients and producers cannot change these circumstances.

This paper follows a previously published journal article entitled, "Towards a free market medical system." That article proposed four things:

1. The patient is responsible for controlling and paying for his or her medical services.

2. The patient funds the cost of medical procedures from a Flexible Savings Account (FSA) invested in the market.

3. The only insurance coverage required under this proposed solution was for catastrophic events. 
4. The patient controls the who, what, where, when, and costs of their healthcare relationships.

The question before us is, "How does the patient manage the fourth activity in a way that generates true free market prices for medicine?" We will not argue the first three points in that paper as they were previously presented and defended, (Appendix A (Shepherd et al., 2011)). This paper will address the solution from the perspective of a desired "perfectly competitive market." We use the word "desired" as the proposed model wishes to attain the conditions of a perfect market, but we know in reality that we would see something akin to a cross between a perfect and monopolistically competitive market - an "Almost Perfect Market" as the paper title proposes.

As a basis for our proposal, we acknowledge the conditions for both perfect and monopolistically competitive markets. These conditions are described in Table 1 - Competitive Market Conditions Comparison.

TABLE 1

COMPETITIVE MARKET CONDITIONS COMPARISON

\begin{tabular}{|c|c|}
\hline $\begin{array}{c}\text { Perfect Competition Conditions } \\
\text { Similarities }\end{array}$ & $\begin{array}{c}\text { Monopolistically Competitive Conditions } \\
\text { Similarities }\end{array}$ \\
\hline Many buyers & Many buyers \\
\hline Many sellers & Many sellers \\
\hline Independent decision making & Independent decision making \\
\hline Firms are profit maximizers & Firms are profit maximizers \\
\hline Freedom to enter and exit & Freedom to enter and exit \\
\hline Firms are profit maximizers & Firms are profit maximizers \\
\hline $\begin{array}{c}\text { Perfect Competition Conditions } \\
\text { Differences }\end{array}$ & $\begin{array}{c}\text { Monopolistically Competitive Conditions } \\
\text { Differences }\end{array}$ \\
\hline The firms' products are identical & The firms' products are different \\
\hline $\begin{array}{c}\text { Buyers and sellers have } \\
\text { perfect information }\end{array}$ & $\begin{array}{c}\text { Buyers and sellers do not have } \\
\text { perfect information }\end{array}$ \\
\hline No market power & Some market power \\
\hline Buyers and sellers are price takers & Buyers and sellers agree on price \\
\hline
\end{tabular}

The proposed market will be typified by a cross-section of Perfect and Monopolistic conditions. The proposal is as follows:

\section{SIMILARITIES BETWEEN MARKET MODELS}

1. Many buyers (patients) - any and/or all U.S. citizens will have access to online accounts, thus providing a common medical services marketplace for both buyers and sellers. E-commerce service providers handling electronic interactions would provide a platform for this marketplace. Buyers can move freely between these service providers at will (as they do today in social-media market providers today.) Buyers may choose to maintain multiple platform accounts.

2. Many sellers - any and/or all medical providers (sellers) will have access to online accounts, thus providing a common medical services marketplace for both sellers and buyers. E-commerce service providers handling electronic interactions would provide a platform for this marketplace. Sellers can move freely between these service providers at will (as they do today in social media market providers today.) Sellers may choose to maintain multiple platform accounts.

3. Independent decision-making - both buyers and sellers can make independent decisions without regard to the other. No intermediary filters or barriers (such as insurance carrier agreements today) exist.

4. Firms are profit maximizers - supply firms are profit maximizers given market conditions. 
5. No barriers to exit or entry - all buyers and sellers have the right to exit or enter the market at any time. Buyers and sellers have the right to move from one service provider to another and/or drop out of the service when so desired.

\section{DIFFERENCES BETWEEN MARKET MODELS}

1. Similar or Dis-similar Products - products can be either similar or dissimilar based on the Current Procedural Terminology (CPT) codes 5 numbered coding methodology. The CPT code-set describes medical, surgical, and diagnostic services. The codes are designed to communicate uniform information about medical services and procedures. Bundling of CPT codes (dis-similar) into desirable units of service is an option for medical service providers. Patients can price and purchase individual or bundled CPT codes to cover their health care requirements.

2. Perfect Information - the electronic marketplace will allow both buyers and sellers to see the whole (desired) marketplace for provided and required services. With the internet providing outsized market information, (you limit the amount of data or regions from which you wish to draw) there are few limits on the market size. Given the problem of multiple service providers for the market platform and individual users or medical providers having only single accounts with one of perhaps many service providers, there may be limitations on the actual market size. Regardless of these problems, from a user (patient/provider) viewpoint medical decisions can be made at a more highly informed level compared to current market methods.

3. Market Power - market power currently resides with insurance carriers and government regulators. Removing these barriers as intermediaries allow both the patient and provider to choose to interact on a one-to-one basis. The service provider as an intermediary does not control the type of transaction between the patient and provider.

4. No barriers to exit or entry - all buyers and sellers have the right to exit or enter the market at any time. Buyers and sellers have the right to move from one service provider to another and/or drop out of the service when so desired.

5. Prices - buyers and sellers agree on a price for individual or bundles of CPT items. These prices are determined through a reverse auction process or at a Buy-it-now price. Price is a win-win agreement point for both parties.

6. Profit Maximizers - firms are profit maximizers in that they participate in transactions for medical procedures up to the point where Marginal Cost equals Marginal Revenue ( $M C=M R)$, after which they drop out of bidding for the patients' medical service requirements. Patients are profit maximizers in that they try to minimize the costs of the requested service to maintain balances in their medical fund accounts.

\section{AN ALMOST-PERFECT MARKET PLACE PROPOSAL}

This paper proposes an online marketplace, which for our purposes will be called mBay (an eBay model for medical services). Patients will maintain an account with all of their medical records in a mBay account. Patient mBay accounts have connections to MedPal (a payment system similar to PayPal that is attached to a patient's market-based Flexible Savings Account). A mBay marketplace is also a place where medical providers can bid (based on criteria set by the patient or on limitations set by the provider) for the patient's business. The mBay service platform will act as a reverse auction and/or marketplace with competing providers bidding down prices to fill available or unsold slots in their services. The patient will always have the ability to "Buy it Now" for any service, avoiding the need to wait and perhaps to select a preferred provider.

The system will use the current CPT coding numbers to allow comparative pricing. Services can be bundled or sought individually by both the patient and the provider. Patients can choose how long to wait, how far to travel, and how much they want to pay before deciding on the provider. 
The benefit to the patient is complete control of the type of service desired (basic - Walmart Flu Shots, or luxury - concierge medical services). Payment through MedPal will remove the exorbitant cost of current insurance filing and paperwork systems, reducing medical practice costs by approximately thirty to forty percent (Shepherd et al., 2011).

Fraud is managed at the patient and provider transaction level. No one spends this or her own money more carefully than they do. An example at the individual level might be: I did not get that shot from my doctor, and therefore I will not pay for that shot. By allowing examination of each transaction at the lowest level, we can almost always ensure patient billing accuracy and the lowest level of transaction reviews.

Following the eBay methodology of ensuring account behavior, there would be rating systems for both patients and providers to provide continuous quality improvement.

\section{PATIENT AND PROVIDER METHODOLOGY}

\section{Required or Optional}

This model does not preclude any patient operating as he or she does today in the selection of services for medical procedures. Even if the patient has an electronic account, it does not stop walk-in or call-in appointments if he or she has an online account in mBay. Walk-in situations would have services provided and then the provider pushing a buy-it-now service bill to the patient's mBay account for a Buyit-Now click and payment through the MedPal system.

Providers would not be required to maintain active accounts on mBay and could take walk-in or callin appointments outside of the system. Payment could be made for services using the FSA card directly from the patient for the complete service provided. Providers might be at an economic disadvantage to not compete for services in the marketplace.

\section{Account Setup}

Patient and provider accounts are set up personally at selected single or multiple service providers. These accounts would be linked through that provider to MedPal accounts. Patient MedPal accounts will source from their FSA funds. Provider Accounts will be Accounts Receivable accounts that accumulate payments and allow tracking for medical audit capabilities.

It would be beneficial to have the service provider maintain the patients' medical records to allow accessibility by any provider. This is not a prerequisite for the system to work. A perfect market system does imply that you might not have one consistent provider. This becomes problematic as you continually shop around for the best solution at the time. Allowing access through this account to all medical records improves the "Perfect Information" argument for implementation.

\section{Search Capabilities \\ Patients}

Search capabilities would work the same as current eBay "purchaser type search capabilities" but revolve around CPT codes, CPT descriptions, keywords, or pushed service information requirements. A pushed service requirement occurs when a medical provider tells a patient that he or she needs single or grouped CPT services as a follow-up to a diagnostic service. Nonprofessional words would also be used in patient search criteria, for example, Allergy injection may be equated to 95115 - Professional services for allergen immunotherapy not including provision of allergenic extracts; single injection.

\section{Providers}

Search capabilities would work the same as current eBay vendor type search capabilities but revolve around CPT codes, CPT descriptions, keywords, or patient pushed service requirements. Nonprofessional words would also be used in provider search criteria, for example, Allergy injection may be equated to 95115 - Professional services for allergen immunotherapy not including provision of allergenic extracts; single injection. 


\section{Codes Classifying Transactions between Patient and Provider}

Medical Categories

Categories for both patient and provider would follow under the following CPT categories with one addition:

$\underline{\text { Category One Codes }}$

- Evaluation and Management: 99201 - 99499

- Anesthesia: 00100 - 01999; 99100 - 99140

- Surgery: $10021-69990$

- Radiology: 70010 - 79999

- Pathology and Laboratory: $80047-89398$

- Medicine: 90281 - 99199; 99500 - 99607

- Other: any CPT code or description

Category Two Codes

- Composite Measures 0001F - 0015F.

- Patient Management 0500F - 0575F.

- Patient History 1000F - 1220F.

- Physical Examination 2000F - 2050F.

- Diagnostic/Screening Processes/ Results 3006F - 3573F.

Category Three Codes

- Temporary codes for emerging technology, services, and procedures.

Note: Medical codes would be associated with common word searches (see Gini description) bridging the gap between professional and non-professional terminologies.

\section{The Patient Decision Process}

Once a patient has an account set up, the decision process will be filtered much the same as we see in the current eBay system.

Search is by category to begin with:

- Medical requirement: CT scan, Blood Test, Cancer Care, Vaccination, Common Cold as an example. These requirements can be searched using common terminology that can be found in a lexicon of terms matching common words with CPT codes.

- Date-Time of Service Desired: Today - a higher price perhaps, call it a buy it now or a lower price when the appointment can be several days away, for example, I need a workplace physical sometime in the next month as opposed to a broken leg bone requiring immediate treatment today.

- Type of service Auction: Is it a "Buy it now" or a" Price Auction." Price auctions are used when you are willing to wait for a response and desire the absolute lowest price.

- Item Location: The distance the patient is willing to travel. This can be in Miles, (I want to stay within 10 miles of home, or I am ready to go 150 miles for service). It could be the USA; I am looking for the best Cancer Services in the United States of America. It could be North America, where I am willing to look in Canada or Mexico (as well as the USA) for Bariatric Surgery as an example. Finally, it may be the World, where I am willing to look at surgeons in Europe or Australia for Melanoma Stage 4 surgery or specialist treatments to save my life.

- Level of service: Concierge - private one-on-one home visits or focused office visits, or Austere - I will go to Walmart for a Flu Shot, cold remedy, or yearly physical.

- Service Provided certification by Specialist, Doctor, Physician's Assistant, Nurse Practitioner, Nurse, Pharmacist, or other desired category.

- Service Provider Type: Private Practice, Practice Chain, Retail Chain, or other.

- Reputation: Provider ratings allow the patient to specify minimum or maximum ratings to include or exclude in search of services. 
- Format: Buy it Now, Auction, or Classified advertisement.

\section{Sort Search Return Performance}

After searching, you will be able to sort your criteria returned in the order you find beneficial. It could be those more costly items that are open today. An example is if you have cut your finger and require stitches.

\section{Patient Bids for Service}

When you click on a service, you wish to be provided that fits your search criteria you have several options.

- You are presented with a Buy-it-now options where (after you have searched and sorted your criteria) you make a bid or buy it now.

- Make an Offer: The patient may want to offer something less than a Buy-it-now price to see if the vendor may take a lower amount

- Auction offer: When making a bid you would be able to have a range for the bid and increments in which you are willing to automatically price up (or manually price) your bids for service.

- Add to your watch list: Patients can add services that are bidding to a watch list where they can jump in and accept a price and or bid up a service as the date and time for the end of the auction nears.

\section{Communications}

Communications between the patient, vendor and service provider will occur through the online platform, an App on a mobile device, or SMS, as set up as preferences in the account setup process. This will be used to provide email feedback on a bid status of "Accepted / rejected, or timed out." An App for mobile devices will allow the patient to be online continually managing his or her requirements. This mimics the patient's current online activity through non-medical sites.

\section{The Provider Decision Process}

Once a provider has an account set up, the decision process will be filtered much the same as we see in the current eBay seller system.

Search structure and categories will be:

- Medical requirement: CT scan, Blood Test, Cancer Care, Vaccination, Common Cold, etc. These requirements can be searched using common terminology that can be found in a lexicon of terms matching common words with CPT codes.

- Date-Time of Service Desired: Today - a higher price perhaps, call it a buy it now or a lower price, when the appointment can be several days away, for example, I need a workplace physical sometime in the next month. Patients that require a service today (but where the provider has no capacity) might be accepted if the price was at a higher price point. This is an incentive to perform for profits.

- Type of service Auction: Is it a Buy it now or a Price Auction? Price auctions are used when you are willing to wait for a response.

- Item Location: This represents the service area that the provider is willing to cover. This can be in Miles, (I want to stay within 10 miles of the office, or I am willing to take patients from 150 miles for service). It could be the USA, were our provider is looking for the patients needing services for Cancer in the United States of America. It could be North America, where I am willing to take patients from Canada or Mexico (as well as the USA) for Bariatric Surgery as an example. Finally, it may be the World, where I am willing to take patients from Europe or Australia for Melanoma Stage 4 surgery or specialist treatments to save their lives. 
- Level of service: I define the level of service I want to provide as a provider. Concierge private one-on-one home visits to focused office visits, or Austere - I am a storefront provider for a Flu Shot.

- Service provided certification by I must specify the certification level or levels serviced by me as a provider. Is it: Specialist, Doctor, Physician's Assistant, Nurse Practitioner, Nurse, or Pharmacist.

- Service Provider Type: What type of provider am I? Private Practice, Practice Chain, or Retail Chain.

- Reputation: Provider ratings allow the patient to specify minimum or maximum ratings to include or exclude in search of services. It is our job to monitor these ratings and address issues to ensure I remain a viable provider of services.

- Format: When we service patient requirements, will that interaction be: Buy it Now, Auction, or Classified Ad?

\section{Sort Search Return Performance}

After searching, providers will be able to sort patients, and their requests returned in the order they find beneficial. It could be, "I have appointment cancellations today that need filling. Who needs something in the window that fills this vacancy?"

\section{Provider Bids for Service}

When you click on a patient that fits your search criteria, you have several options. You are presented with:

- Buy-it-now options: where you can see open or accepted buy it now options you have entered for service possibilities.

- Make an Offer: As a vendor, you may want to offer something less than a Buy-it-now price to see if the patient may take a lower dollar value.

- Auction offer: When making an offer you would be able to have a range for the offer and increments in which you are willing to automatically price down (or manually price) your bids for service.

- Add to your watch list: Providers can add patient services that are bidding to a watch list where they can jump in and accept a price and/or bid down a service as the date and time for the end of the auction nears.

- Bundles: Providers should be able to bundle services to create price differentiation points. This differs from perfect competition models. An example would be concierge level services where services may be offered except for certain high-priced services.

\section{Communications}

Communications between the patient, vendor and service provider will occur through the online platform, an App on a mobile device, or email, or SMS as set up as preferences in the account setup process. This will be used to provide email feedback on a bid status of "Accepted / rejected, or timed out." An App for mobile devices will allow the provider to be online continually managing this or her requirements. This mimics the vendors' current online activity through non-medical sites.

The complexity of CPT medical codes will require an intermediary process that helps users interpret the medical codes, jargon, and service combinations required to use the service successfully.

In situations where a patient is with a provider who suggests services, the provider can recommend medical codes that cover the desired services to be provided. We estimate about $50 \%$ of the medical services being requested will be able to be suggested with accuracy by the provider. An example would be where a patient has gone to a family practice professional for a consult (he or she would search or enter for this service). If the family practice provider suggests bloodwork, urinalysis, and a CAT scan, then the 
provider suggests the codes be bid or sought by the patient. These services codes could even be pushed to the patient through SMS or messaging within the service provider.

In situations where patients know they need a service but are unsure as to what codes to use, there is a need for what we might call a "Genie" (Martin, 2018), or Alexa type interpreter, who listens to the type of service that the patient may require and then suggests, using non-detailed medical terminology, the type of service code. This "Genie" will learn similarly to Alexa and current software autocorrect functions the idiosyncrasies of each patient and help interpret code requirements for services being sought.

\section{Start-Up Online Service Providers}

There are several similar service providers out there today who will be capable of quickly providing this type of service. eBay and Amazon will be immediate contenders and with their PayPal interfaces be quickly able to re-design (or re-create) their current systems to enable the suggested processes. Facebook and other services (through their market place applications) may also be able to contend in this market. Users will want non-platform specific options allowing them to choose platforms that conform most closely to their preferences. A broad number of platform providers makes for a more difficult medical provider interface as each provider vies for services to fill daily openings. A systematic approach to multiple service providers would allow a medical service (family practice as an example) to bid across platforms for open family practice appointments during the current service day.

\section{Near Perfect Competition}

Perfect (or near perfect) competition ensures that companies are operating at or near the lowest point on the cost curve. In these circumstances, providers can offer services at their lowest price to patients. By providing a marketplace that is genuinely price/profit driven (at its base level) patients can shop for services at prices that meet the expectations for that service. Patients who desire price based services can opt for low price (or lowest price) services by non-specific providers, while those who want services from a current known provider can use a buy-it-now type of approach with their existing service provider. The process of disenfranchising the insurance companies from the decision-making process ensures that we empower the end user most expeditiously and beneficially to expend their medical savings account dollars.

\section{Ratings}

The perfect market works off perfect information. This perfect information must include both patient and provider performance ratings as currently found in websites such as eBay and Amazon. These userrating systems embed a performance measurement system that ensures that both patient and provider can make informed decisions about the quality of the provider and patient.

Both patients and providers can require different levels of compliance if the ratings are poor. An example might be if a patient rating is low for payment issues, then a provider may require a buy-it-now payment before services being provided. Patients may also review provider ratings and pay only lower prices based on lower performance expectations.

\section{Auditing}

With a perfect market system, we have patients reviewing transactions, providers verifying that services were received, and both knowing that the agreed price was paid for actual line items. Currently, there is no line item auditing of all transactions. The patient has fallen into a moral hazard by being disenfranchised from the actual medical transaction costs. When it is no longer his or her money being spent, patients do not audit transaction costs after deductibles are met. This allows the possibility of fraud and/or medical expenditure mismanagement.

The sheer volume of line item transactions in current medical transactions is almost immeasurable. Patients in non-medical transactions know the price of each line item they are purchasing. A checkout transaction is always questioned when there is a price variance. The same is true for providers. If a revenue transaction is unpaid, the provider knows of it. As end users, we (both patients and providers) all 
review our purchase transactions to ensure we get our value for funds expended. This process ensures we have every patient and provider auditing their expenditures or revenue transactions.

The time and cost savings in not dealing with insurance or government entities reduces transaction costs for both the patient and the provider. Reduced costs increase profit margins and the incentive to offer more or improved services. The accuracy of patient and provider self-auditing will always outperform statistical sampling at the macro level by insurance companies and government offices.

\section{LITERATURE REVIEW}

Curtis Dubay from The Heritage Foundation (Dubay, 2013) believes that legislation in the Obamacare provision has eroded the doctor (provider) and patient relationship. That legislation has centralized more control with the government and increased health care costs. He posits, "True health care reform would empower individuals, with their doctors, to make their own healthcare decisions free from government interference. Therefore, Obamacare should be stopped and fully repealed. Then Congress and the states should enact patient-centered, market-based reforms that better serve Americans." While Dubay focused on Patient Choice and Competition, he limited himself to the patient choosing his or her health care insurance plans and working with his or her own portable and flexible health savings accounts. He stops one step short of placing direct negotiating control with the patient as suggested in this paper.

Bobic in his interview with Ben Carson, who at the time was running for president, drew Carson out on his position concerning the current health care situation (Bobic, 2015). The presidential hopeful called the health care law "completely antithetical of the principles" of the Founding Fathers, and instead called for replacing it "with something that really puts the power back in the hands of patients and providers." Carson also is a proponent of Health Savings Accounts that support an individual's choices. Carson said that he "supports creating health savings accounts to which pre-tax funds can be contributed, allowing patients to shift amounts around within their family." The flexibility (to move funds along with free choices) is fundamental to ensuring true (near) perfect market conditions in the health care market.

Dalrymple (2012) interviewed John C. Goodman, author of the book Priceless: Curing the Healthcare Crisis. In that book, Goodman has some radical proposals for America's ailing healthcare system. "If you want to help the poor, " he suggests," the best approach is to restore free-market pricing mechanisms into the market for medical care and health insurance." Goodman asks the following questions, "How long does it take you on the telephone to get an appointment to see a doctor? How many days do you have to wait? How long does it take to get from your home to a doctor's office, and how long do you have to wait after you arrive?" Goodman tells us that these are all non-price barriers to care, and "there's plenty of evidence that those barriers are more important than the fee the doctor charges, even for low-income people." Goodman says, "In the United States, we - just like the Canadians and the British and people all over Europe - primarily pay for care with time and not money. And paying with time turns out to be a very wasteful and inefficient way to pay for care."

Goodman says, "The main point is that in health care we have completely suppressed the marketplace, so much that no one sees a real price for anything in the health care system proper. No patient, no doctor, no employee or employer. As a result, we all have perverse incentives. On the buyer side, our incentives are to over-consume, and often to consume the wrong kinds of services. On the supplier side, the incentive is to over-provide. Obamacare, in an attempt to control costs, will create incentives for the providers to under-provide. The way out of this is to allow real prices to allocate resources so that people face good incentives instead of perverse incentives." (Dalrymple, 2012) Patient and provider contact through a mBay type of perfect market allows both to control the variables in which they place value. In some cases, it is cost. In other cases, it is the time or level of service.

Most Americans view their healthcare system as "free-market." This is not so. According to HoltzEakin, et al. (2013) "In fact Switzerland actually has the most market-oriented healthcare system in the West. It translates into universal coverage and low entitlement costs. Swiss government entities spent about 3.5 percent of gross domestic product on healthcare in 2010, compared to 8.5 percent in the United States. That is a difference of more than $\$ 5$ trillion over ten years: real money, especially relative to our 
$\$ 16$ trillion debt. There is no "public option" in Switzerland. Instead, citizens qualify for means-tested, sliding-scale subsidies and choose among a variety of regulated, private-sector insurance products. The Swiss have the freedom to choose their own doctors, as Americans do, and access to the latest medical technologies. They also have short waiting times for appointments." While more free than the American system, the Swiss system still controls funding for medical procedures and means tests people for funding. The proposed mBay system does not do that.

In his commentary piece, Wendell Potter (Potter, 2015) speaks of author Steven Brill's book "America's bitter pill." In this book, Brill examines the circumstances around the expenses he incurred for aortic aneurysm surgery. The costs of parts of that surgery were thought to be exorbitantly high. Brill said, "The cost of room and board alone at New York-Presbyterian hospital was \$63,000. The hospital also charged thousands more for things like 'patient education,' which Brill said he doesn't even recall receiving." Brill lamented the fact that these charges were higher than in recent years because servicing hospitals had become larger and therefore gave fewer discounts to insurers. These increased prices, from the author's perspective, show that the free market is failing. What the author fails to understand are the basic tenets of what makes up a free market in medicine. He speaks of some 1,300 insurance companies as if they represent the "free market." The connection to individuals is lost. He cannot see a solution where patients can select, control, and or negotiate their solutions to health care.

Sinha (2018) posits that there are free market examples in health care that fail. In his blog, he speaks of the medical system in India where everyone has access to a mostly unregulated industry. The country even uses eBay to buy and sell medical services (much as this paper maintains). Sinha ultimately says that the free market fails because there is a natural exclusion of patients because of inability to pay. It is this paper's position that this argument ultimately fails. Exclusion through inability to pay does not cause the process to fail. The process in and of itself is successful in its activities. The question becomes, "How to include the otherwise excluded?" An example of this argument failing is that of free markets for food. We do not exclude the poor from free markets for food, and yet they cannot afford to eat. Does that preclude us from (as a society) benefiting from the free market where food is available to all, but not used by all? This argument tosses the baby out with the bath water.

Sinha (2018) says, "You see, Healthcare cannot be free market because one party (the patient) is at a resource disadvantage by definition. Resource disadvantage means the person seeking the care does not have the resources necessary to support their side of a free market negotiation." He maintains that patients are at a disadvantage because they don't have, "the time or the ability to shop around or negotiate rates, they lack the skill and know-how to figure out what's necessary and what's not, and the customer has to be able to choose the null outcome - walk away from the deal if it's not in budget." What is assumed in these three statements is that all are true because "they" say they are true! These statements are not true for all societies. In a market where you have "buy it now" capability, in a mobile society such as the U.S. economy, and in an electronic market where we click "out of" transactions daily, we operate in an empowered and knowledgeable user environment.

The argument against the use of technology due to technology ignorance fails when seen in the light of adoption rates for technology in these past decades. Cell phones (phone calls), laptops (information manipulation), iPhones (phone calls with web-based applications), Social Media (social connections) all have incredibly fast adoption rates. The benefits of technology undoubtedly bind the future. To ignore that fact when positing new solutions limits the future capabilities of a real free market system.

Jha (2015) states, "Advocates of more market and less government in healthcare balk at these stories [medical care refused for payment]. They protest that a market does not mean letting someone die in the street." Indeed, it does not. But a market is no less a market just because a surgeon refuses to operate on a dying man because he can't pay. The key ingredient of a market is the voluntary nature of the doctorpatient relationship. You could force a surgeon to operate on the dying, regardless of his ability to pay. But that would require government fiat, and it would be less free, even if more humane, market." He says, "To say that private medicine in India is not a free market just because it does not always deliver the ethics and results we expect, is to hold the definition of market hostage to its outcomes." 
Goodman (one of the nation's leading thinkers on health policy) proposes a free market where medical service providers advertise to draw patients. "If we had a genuinely free market for health care, ads like this would not be rare and unusual. There would be centers of excellence for heart disease and diabetes and dozens of other afflictions. Through television, radio, the Internet and other means, these centers would be seeking out people with problems and offering to solve them - just like in other markets. Unlike today - when virtually every health plan, especially in the Obamacare exchanges, is trying to avoid the sick - entrepreneurs would view the healthy as relatively uninteresting. It is among sick people with expensive problems that real money is to be made." Goodman sees a market where excellence is focused on the needy through these free markets.

\section{A PROVIDER PERSPECTIVE ON LESSENING PROFITS IN THE MODERN HEALTHCARE INDUSTRY}

The US healthcare system has been increasingly stressed. The healthcare industry, while essential to the continued success and health of our country's citizens, has been neglected for far too long. A large portion of the for-profit acute care facilities in the United States is considered financially stressed (Gooch, 2018). This means that they are facing challenges such as: struggling to meet payroll, vendors only dropping off supplies when paid cash at the loading dock, and the inability to reinvest in the infrastructure of the facility. This industry strain was further complicated in 2008 with the passage of the Affordable Care Act (ACA) (LaPointe, 2016). This act was implemented with good intentions on the wings of public cries for healthcare reform. Why not? Cheaper and more easily accessible healthcare sounds like a good idea. However, what happens when an already financially stressed system's profits are reduced even further by government legislation?

One challenge with the ACA was its Medicare Reimbursement. Hospitals receive performance rankings called Hospital Patient Assessment of Healthcare Providers (HCAHPS) that grade their hospital on many criteria. Before the Affordable Care Act, if you had an "A" HCAHPS score, you received a 3\% Medicare Reimbursement. After the ACA hospitals only received a 1.5\% Medicare Reimbursement for the same HCAHPS grade (Hcahpsonline.org, 2019). This change does not sound like a lot, but the reality is that this dollar difference for healthcare systems could vary by hundreds of millions of dollars. The service expectations of the patient did not change. The hospital's expenses for equipment, supplies, and staff did not decrease for the procedure. Now the reimbursements are cut in half for doing the same job.

Patients have all been frustrated at one point or another with the outrageous charges from their hospital visits. The question arises, "Why are these charges so high?" The truth is that under the current system, providers only collect a minute amount of each dollar (Belk, 2018). This is because most hospital patients do not pay their bills. The industry faces a high-cost service with zero revenue to cover the services provided. Uninsured patients have to be treated by hospitals even though they cannot pay. For each insured patient, a for-profit healthcare facility will only collect between thirteen to fifteen cents on the dollar. For uninsured or Medicaid patients hospitals will only collect three to five cents on the dollar. Suddenly those for-profit prices may not seem so steep.

The healthcare industry was designed to be a much-needed service to meet the need of our country. At the core of for-profit healthcare is the undeniable truth that businesses cannot run at a loss and still meet the needs of their patients and staff. So where does the healthcare industry turn to maximize their dwindling profits? Process improvement, turnover reduction, and delaying the purchasing of muchneeded equipment is the usual solution to the problem. From a Healthcare Human Resources perspective providers spend the majority of their time finding ways to recruit and retain more staff. This is because the patients do not care if the for-profit healthcare provider is financially stressed. Providers also look for non-essential functions that do not make money but help them compete for patient business. If providers are faced from a business perspective with the prospect of losing a service line or a coffee shop that the patients love, they will pick the coffee shop every time.

So how can this be corrected? These authors assert that if a healthcare model existed where patients had the means and convenience to pay their entire bill within the month, it would increase the profitability 
of the healthcare industry, resulting in millions of much-needed profits being rolled back towards the patients. For example, if hospitals had more profit from better patient payments, they could ensure that clinical staff received competitive wages at all times. This would mean that if you came to a facility, you would have the best employees that money could buy. Service quality, range of services, and both employee and patient satisfaction would improve. More Coffee and gift shops, educational support groups, and community outreach and education would take place. The system would work better.

Furthermore, hospitals could reinvest these profits in the infrastructure of their facility to become more competitive; offer different or better service lines. If a competitor had a Mammography machine, and they could now afford to offer 3D Mammography, they would be more competitive in the market; and the patient would receive better care. In essence, the patient would see a near perfect market system improving the health care of the provider as well as the patient.

\section{CONCLUSION}

The American health care system does not operate in a real free market environment. The patient cannot manage his or her healthcare services and control his or her costs. This paper proposes we implement an almost perfect competition model that has: (1) Many buyers, (2) Many sellers, and (3) Perfect information. The meeting place for the solution to these requirements generates an almost perfectly competitive market for medicine and returns almost complete control to the patient. This meeting place is an online auction/marketplace service. The service acts as a reverse auction or marketplace with competing providers bidding down prices to fill available slots in their services. The system uses current medical coding numbers to allow comparative pricing with the addition of a Gini system to learn user requirements and create a smooth terminology interface. Services in the market can be bundled or sought individually by both the patient and the provider. Patients can choose any market variable as a price variant. How long to wait, how far to travel, and how much they want to pay before deciding on the provider is at their control.

By systematizing the process using known and commonly used platform examples, we ensure that medical standards are met and terminology is consistent while enabling patients and providers to access improved services at lower market prices.

By providing systematized methods to manage this complex process, we:

- Are giving more power to the patient.

- Are giving more power to the provider.

- Are removing moral hazard as a problem in patient transaction costs.

- Ensure ownership and control of medical outcomes at the lowest level.

- Create a profit motive where service price covers competitive service costs rather than insurance table costs (price controls).

- Ensure increased numbers of providers as they enter the market to compete for profits.

- Ensure that price signals indicate what services are required where.

- Ensure provider competition and, through market interaction, the lowest price possible.

- Create auditing accountability and consistency by forcing transaction cost audits to the lowest level - the patient and provider.

- Increase profits for providers.

- Remove significant overhead costs for insurance and government processing.

The following list sets out concerns with the process.

- With an aging population, we will always have legacy issues with non-participating vendors and patients. Technology barriers may limit participation in the short term.

- Education levels may also be a limiting factor. We always assume that patients operate in their own best interest. This may not be so for situations where the patient or provider competency is a problem. 
- There is also the disjoint between a patient and a medical professional's terminology. Until cross-references between tables and verbal descriptions occur (the interpretive Gini), there may be search and purchase problems.

A near perfect market, internet-based transaction system will ensure that market forces control transaction costs, increase service availability, and improve the medical outcomes of all in the US economy.

\section{REFERENCES}

Belk, D. (2018). Hospital Billing. Retrieved February 26, 2019, from http://truecostofhealthcare.org/hospitalization/

Bobic, I. (2015). Ben Carson: Replace Obamacare Before Repealing It. Retrieved from https://www.huffingtonpost.com/entry/ben-carson-obamacare_us_55bff0dae4b06f8bedb5c422

Dalrymple, T. (2012). Want to Help the Poor? Promote a Free Market in Health Care. Retrieved from https:/www.patheos.com/blogs/philosophicalfragments/2012/09/29/john-c-goodman-want-tohelp-the-poor-promote-a-free-market-in-health-care/

Dubay, C. (2013). After Repeal of Obamacare: Moving to Patient-Centered, Market-Based Health Care. Retrieved from http://www.heritage.org/research/reports/2013/10/after-repeal-of-obamacaremoving-to-patient-centered-market-based-health-care

Gooch, K. (2018). How financial distress forecasting can help hospitals avoid closure: Hospitals are increasingly experiencing financial hardships due to factors such as changing reimbursement models, lower patient volumes and more competition in some markets. Retrieved from https://www.beckershospitalreview.com/finance/how-financial-distress-forecasting-can-helphospitals-avoid-closure.html

Goodman, J. C. (2017). What Would A Free Market For Health Care Look Like? Retrieved from https://www.forbes.com/sites/johngoodman/2017/04/10/what-would-a-free-market-for-healthcare-look-like/\#6a69fc92e445

Hcahpsonline.or. (2019). Retrieved from https://www.hcahpsonline.org/ Sponsored by the Centers for Medicare and Medicaid Services.

Holtz-Eakin, D., \& Roy, A. (2013). The future of free-market healthcare. Retrieved from http://blogs.reuters.com/great-debate/2013/02/20/the-future-of-free-market-healthcare/

Jha, S., Dr. (2015). Private Medicine in India is a Free Market. Retrieved from $\mathrm{http}: / /$ thehealthcareblog.com/blog/2015/10/01/private-medicine-in-india-is-a-free-market/

LaPointe, J. (2016). How the Affordable Care Act Impacted Healthcare Revenue Cycle. Retrieved from https://revcycleintelligence.com/news/how-the-affordable-care-act-impacted-healthcare-revenuecycle

Martin, T. (2018). Personal Interview with I. Shepherd.

Potter, W. (2015). Free market ideology doesn't work for health care. Retrieved November 14, 2018, from https://www.publicintegrity.org/2015/06/08/17460/free-market-ideology-doesnt-workhealth-care

Shepherd, I., \& Shepherd, D., (2011). Towards a "Free Market" Medical System. Journal of Applied Business and Economics, 2(12).

Sinha, S. (2018). Are-there-any-free-market-based-healthcare-systems-anywhere-in-the-world-that-work. Retrieved from https://www.quora.com/Are-there-any-free-market-based-healthcare-systemsanywhere-in-the-world-that-work. This is a blog discussion site.

2.07: Intro to CPT Coding. (2018). Retrieved from https://www.medicalbillingandcoding.org/intro-to-cpt/ 


\section{APPENDIX A}

\section{Towards a "Free Market" Medical System - Model Variables (Shepherd, 2011)}

1. Unused Funds (UF) - At birth, this fund has a zero balance. Each year, unused funds are recycled through the market to grow at market rates.

2. Private Funding (PF) - Individuals can deposit pre-tax dollars into the fund for personal coverage.

3. Corporate Funding (CF) - Individuals negotiate with corporations as part of employment contracts to mutually agree on corporate funds deposited to their accounts.

4. Government Funding (GF) - A seed amount is determined and added at significant life events, e.g., birth amount, savings goal amount, or retirement amount.

5. Gift Out (GO) - Consumers can gift any amount to another individual tax-free.

6. Gift In (GI) - Consumers can accept gifts of any amount from another individual tax-free.

7. Market Growth (MG) - Unused funds are invested in the market and grow at market rates.

8. Catastrophic Coverage (CC) - Catastrophic coverage is offered to handle extreme emergencies with high deductibles, e.g., $\$ 100,000$ minimum.

9. Medical Expenses (ME) - Medical expenses are those costs incurred by the consumer and paid for out of Unused Funds.

\section{FIGURE 1}

\section{CIRCULAR FLOW MODEL FOR FREE MARKET MEDICINE}

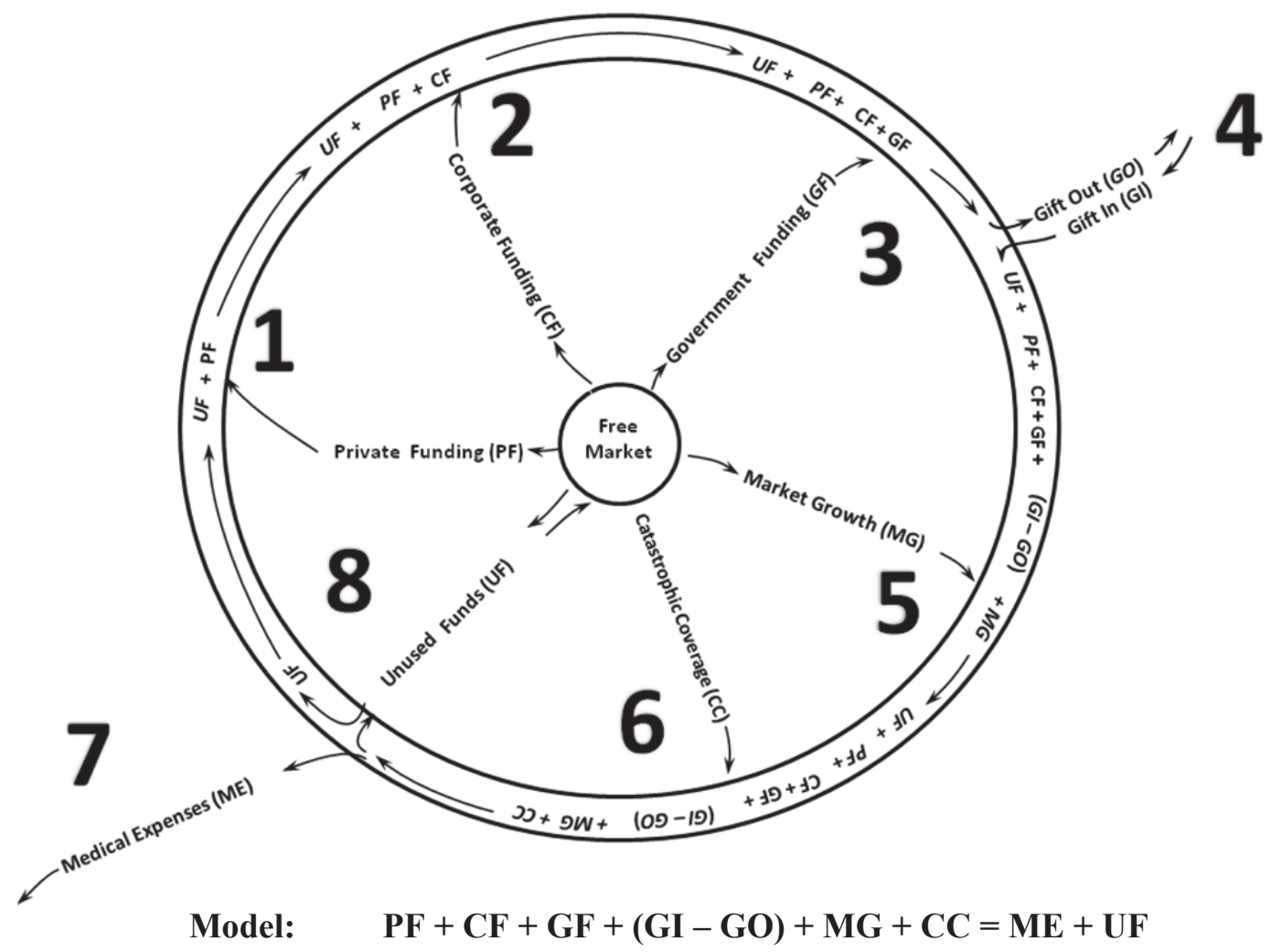

Note: This model ignores all free market interactions outside of the funding for consumers. Once freedom of choice in medical care has been established, the free market mechanisms of supply and demand will equilibrate the supply and demand for services in mutually agreeable locations at mutually agreeable prices. 